\title{
Teknologi Pengolahan Cabe Merah Bagi Kelompok Wanita Tani Desa Sukasari Kabupaten Kepahiang
}

\author{
Novitri Kurniati $^{1}$, Jafrizal ${ }^{2}$, Fithri Mufriantie ${ }^{3}$ \\ ${ }^{1}$ Prodi Agribisnis Fakultas Pertanian, ${ }^{2}$ Prodi Agroteknologi Fakultas Pertanian, ${ }^{3}$ Prodi Agribisnis Fakultas Pertanian \\ ${ }_{1,2,3}$ Universitas Muhammadiyah Bengkulu \\ e-mail: ${ }^{1}$ noviewin@gmail.com, ${ }^{2}$ jafrizalumb@gmail.com, ${ }^{3}$ fithrimufriantie@yahoo.co.id
}

\begin{abstract}
Abstrak
Sampai saat ini petani cabe di Kabawetan masih mengantungkan usahanya pada penjualan cabe segar. Keterbatasan pengetahuan dan keterampilan petani menyebabkan mereka sama sekali belum mampu mengolah hasil panen cabe menjadi produk pangan lainnya yang memilki nilai tambah dan masa simpan yang lebih lama. Berdasarkana diskusi dan masukan dari ibu-ibu anggota kelompok wanita tani, disepakati untuk memberikan sentuhan teknologi pengolahan pada produk cabe segar yang dihasilkan petani. Disamping menghasilkan produk yang memilki nilai tambah juga sebagai upaya antisipasi kelangkaan cabe pada saat harga melonjak tinggi. Cabe merah diolah menjadi cabe kering, cabe bubuk, abon cabe, pasta dan aneka saos cabe. Solusi ini dipilih dan disepakati dengan pertimbangan pembuatannya sangat mudah dan bahan bahan bakunya sangat melimpah di Kecamatan Kabawetan. Bentuk kegiatan yang dilakukan diantaranya berupa; pendidikan dan penyuluhan tentang pengolahan pascapanen produk sayuran; pelatihan dalam pembuatan cabe kering, cabe bubuk, abon , pasta dan saos cabe merah. Kegiatan pengabdian yang telah dilakukan dapat meningkatkan keterampilan ibu-ibu petani dalam mengolah cabe merah, mengurangi kerugian petani disaat harga anjlok dan bisa menjadi usaha sampingan bagi ibuibu petani cabe sehingga dapat meningkatkan penghasilan keluarganya.
\end{abstract}

Kata kunci: bubuk; abon; pasta; saos cabe

\begin{abstract}
Until now, chilli farmers in Kabawetan still rely on selling fresh chillies. The limited knowledge and skills of farmers have made them completely unable to process chilli crops into other food products that have added value and a longer shelf life. Based on the discussion and input from the women members of the women farmer group, it was agreed to give a touch of processing technology to the fresh chilli products produced by farmers. Besides producing products that have added value as well as anticipating anticipation of scarcity of chilli when prices soar. Red chillies are processed into dried chili, chili powder, shredded chili, pasta and various chili sauce. This solution was chosen and approved considering that the manufacturing is very easy and the raw material is very abundant in Kabawetan District. The form of activities carried out. education and counseling about postharvest processing of vegetable products; training in making dried chili, chili powder, shredded rice, pasta and red chili sauce. The service activities that have been carried out can improve the skills of farmers 'mothers in processing red chillies, reduce farmers' losses when prices plummet and can become a side business for chilli farmer mothers to increase income.
\end{abstract}

Keywords: powder; abon; pasta; chili sauce 


\section{PENDAHULUAN}

Kecamatan Kabawetan adalah salah satu dari delapan kecamatan yang ada di Kabupaten Kepahiang dengan luas daerah 6.331 ha atau $10 \%$ dari luasan kabupaten secara keseluruhan. Ibu kecamatan (Kelurahan Tangsi Baru) berjarak $10 \mathrm{~km}$ dari ibu kabupaten dan $75 \mathrm{~km}$ dari ibu kota Propinsi Bengkulu. Kecamatan ini memiliki karakteristik yang berbeda dengan tujuh kecamatan lainnya. Kontur tanahnya berbukit, ketinggian 600- $1200 \mathrm{~m} \mathrm{dpl,} \mathrm{suhu} \mathrm{rata-rata} \mathrm{16-}$ $28{ }^{\circ} \mathrm{C}$, curah hujan rata-rata 5 tahun terakhir 3.321,60 $\mathrm{mm} /$ tahun dengan jumlah bulan basah 8-10 bulan. Kondisi alam yang sejuk ini menjadikan Kecamatan Kabawetan sebagai salah satu sentral perkebunan (Kebun Teh Kabawetan), pertanian dan peternakan yang terkemuka di Propinsi Bengkulu.

Usaha pertanian yang utama adalah padi sawah, palawija dan aneka tanaman sayuran. Produk palawija yang meninjol diantaranya jagung pakan ternak, jagung manis dan ubi-ubian. Tanaman sayuran yang banyak diusahakan diantaranya cabe merah keroiting, cabe rawit, kentang, bawang daun, kubis/kol, sawi/petsai, tomat, terong, wortel, kacang buncis, kacang panjang dan labu siam. Khusus untuk tanaman cebe merah keriting, produksi pada tahun 2016 mencapai 1.554 ton [1]. Disamping untuk memenuhi kebutuhan pasar lokal Kabupaten Kepahiang, produk cabe merah daerah ini juga dipasok ke Kota Bengkulu dan ke beberapa daerah di Propinsi Sumatera Selatan.

Akan tetapi sampai saat ini petani cabe di daerah ini hanya mengantungkan usahanya pada penjualan cabe segar. Petani cabe merah didaerah ini belum mampu mengolah cabe merah menjadi aneka olahan cabe. Melaui Program Kemitraan Masyarakat (PKM) disepakati dengan kelompok tani mitra untuk melaksanakan kegiatan pengabdian masyarakat dengan tema teknologi pengolahan cabe merah.

Tujuan dari kegiatan PKM yang dilaksanakan adalah untuk memberikan pengetahuan dan keterampilan kepada kelompok mitra sasaran dalam mengolah cabe merah menjadi aneka olahan cabe melalui transfer dan penerapan teknologi tepat guna pengolahan cabe merah.

\section{SUMBER INSPIRASI}

Sebagaimana sifat tanaman hortikultura adalah kehilangan hasil tanaman berupa penurunan kuantitas maupun kualitas. Penurunan kuantitas diantaranya berupa penurunan bobot dan hilangnya produk akibat kerusakan atau pembusukan, baik sebagian ataupun seluruhnya [3]. Untuk cabe merah dalam bentuk segar memiliki daya simpan yang tidak lama akibat kerusakan mikrobiologi atau fisiologi karena serangan mikroba Colletrothicum capsici dan kerusakan fisiologis karena proses respirasi buah pada saat penyimpanan cabe merah [2].

Permasalahan umum dalam usaha budidaya cabe merah yang juga dirasakan oleh petani cabe merah di Kecamatan Kabawetan adalah fluktuasi harga yang tingga dalam waktu yang tidak bisa diprediksi oleh petani. Saat panen raya maka harga yang anjlok dan tidak tidak sebanding dengan biaya produksi. Khusus pada petani di Kabawetan, karena daerahnya termasuk dataran sedang, cabe yang dihasilkan petani lebih tinggi kandungan airnya. Hal ini menyebabkan cabe merah dari Kecamatan Kepahiang kalah bersaing dengan cabe yang berasal dari dari Padang dan Pulau Jawa.

Keterbatasan pengetahuan dan ketrampilan petani menyebabkan mereka sama sekali belum mampu mengolah hasil panen cabe menjadi produk pangan lainnya. Untuk itu tepat bila cabe merah tersebut diolah menjadi produk pangan yang bisa memperpanjang masa simpan, memiliki nilai tambah dan murah.

Apabila solusi yang telah disepakati lebih mudah diterima dan diserap oleh masyarakat petani maka teknologi yang dipilih haruslah sederhana, murah, mudah dilaksanakan dan berbasis pada potensi lokal. Berdasarkan diskusi dan masukan dari anggota kedua kelompok calon mitra disepakati produk cabe merah yang dipilih adalah cabe bubuk, abon cabe, dan saos cabe merah. 


\section{METODE KEGIATAN}

Beberapa tahapan kegiatan yang dilakukan guna mencapai tujuan dan target yang telah ditetapkan pada Program Kemitraan Masyarakat (PKM) di Desa Sukasari Kecamatan Kabawetan diantaranya: 1) Pendidikan dan Penyuluhan tentang tekonologi pengolahan hasil pertanian tanaman hortikultura (sayuran) yang dapat meningkatkan nilai tambah dan memperpanjang masa simpan produk tanaman hortikultura terutama tanaman cabe, 2) Pelatihan pembuatan cabe bubuk, abon cabe, pasta cabe dan aneka saos cabe, dan Pendampingan.

\section{KARYA UTAMA}

\section{Persiapan}

Pada tahap persiapan telah dilakukan koordinasi dengan kedua kelompok tani mitra kegiatan pengabdian. Disamping itu juga dilakukan kordinasi dengan aparat pemerintahan Desa Sukasari. Dalam koordinasi dengan kedua mitra hal-hal yang dibicarakan antara lain waktu pelaksanaan, tempat pelaksanaan kegiatan, alat dan bahan yang dibutuhkan dalam pelaksanaan program pengabdian.

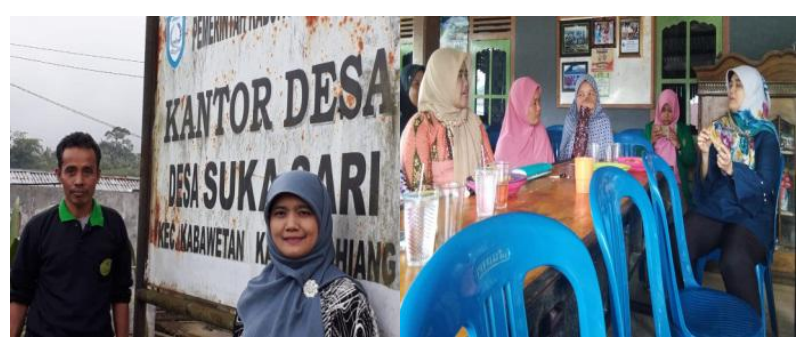

Gambar 1. Sosialisasi ke Pemerintahan Desa dan Kelompok Wanita Tani

Dalam diskusi juga diminta masukan dari kedua kelompok tentang tahapan dan metode pelaksanaan kegiatan. Dari koordinasi yang telah dilakukan, didapat kesepakatan diantaranya kegiatan pendidikan dan penyuluhan dan pelatihan dipusatkan di ruang pertanian kelompok tani yang ada di Dusun 3 Desa Sukasari. Untuk materi pelatihan selain cabe kering dan cabe bubuk, juga disepakati untuk membuat abon cabe, pasta cabe dan aneka saos cabe seperti saos cabe murni, saos cabe tomat, saos cabe nanas dan lain-lain yang bahannya mudah didapatkan dilingkungan petani. Agar kegiatan lebih efektif, pertemuan juga menyepakati bahwa semua kegiatan hanya diikuti oleh perwakilan kedua kelompok wanita tani yang masing-masing nya diwakili 4 sampai dengan 6 orang per kelompok kecuali pada kegiatan penyuluhan yang boleh diikuti oleh seluruh anggota kelompok mitra.

Pada saat koordinasi dengan tim juga diinformasikan bahwa kegiatan pengabdian ini tidak hanya dihadiri oleh tim inti pelaksana kegiatan yaitu 3 orang dosen, akan tetapi direncanakan juga akan melibatkan beberapa mahasiswa dari Fakultas Pertanian Universitas Muhammadiyah Bengkulu. Hal ini dilakukan disamping untuk menambah wawasan mahasiswa dalam praktek usaha pertanian, juga ditujukan sebagai ajang promosi bagi Universitas Muhammadiyah Bengkulu terutama bagi prodi-prodi yang ada di lingkungan Fakultas Pertanian.

Setelah melakukan koordinasi dan kesepakatan dengan kedua kelompok, tim pelaksana kegiatan mulai menyiapkan alat dan bahan. Alat yang dibeli/dipesan diantaranya spanduk kegiatan, mesin penepung cabe kering, kompor gas beserta regulator, blender, dandang, panci stainless, kuali stainless, baskom, timbangan, ember pisau, toples, ember, gelas ukur, nampan, botol kaca dan botol plastik dan bahan-bahan yang dibutuhkan dalam kegiatan program pengabdian.

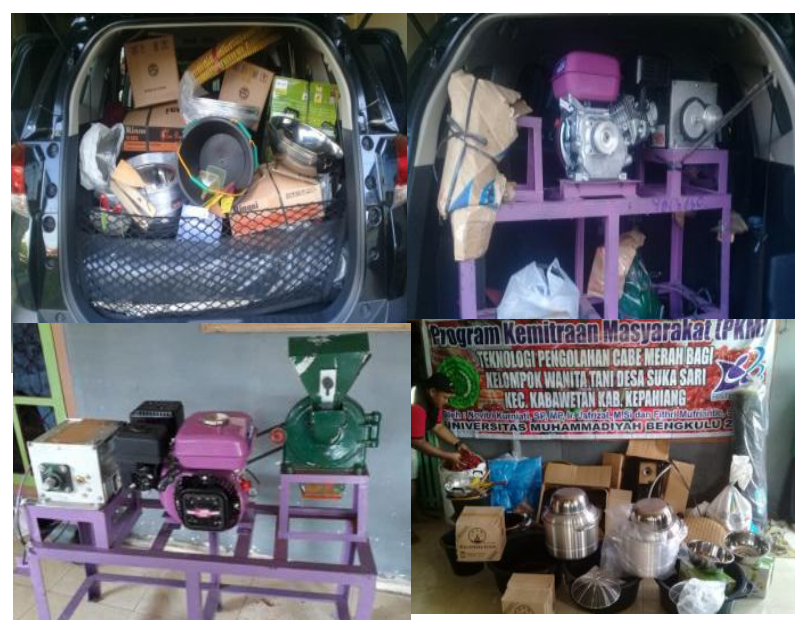

Gambar 2. Droping Alat dan Mesin Kegiatan PKM 


\section{Pendidikan dan Penyuluhan}

Sesuai dengan kesepakatan sebelumnya dengan kelompok tani mitra, kegiatasan pendidikan dan penyuluhan hanya difokuskan pada satu lokasi yaitu di ruang pertemuan Kelompok Tani Desa Sukasari.

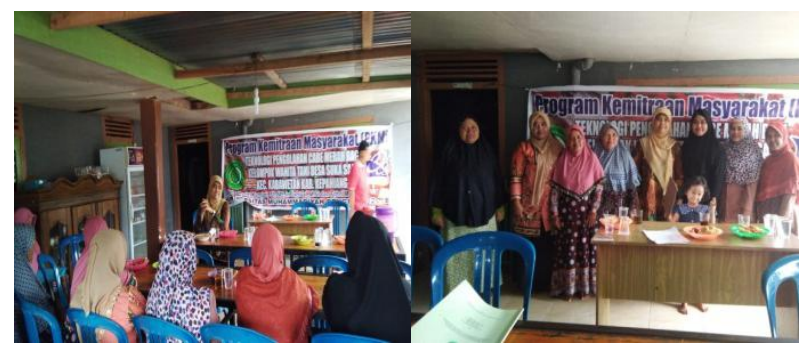

Gambar 3. Kegiatan Pendidikan dan Penyuluhan

Kegiatan pendidikan dan penyuluhan diisi dengan materi yang berkaitan dengan topik PKM diantaranya aneka teknologi pengolahan pasca panen cabe pada umumnya. Acara penyuluhan diawali dengan presentasi dari tim pelaksana dan dilanjutkan dengan diskusi/tanya jawab. Acara dikondisikan akrab dan penuh kekeluargaan. Alat bantu yang digunakan disamping fotocopian makalah juga didukung dengan tampilan powerpoint menggunakan LCD projektor. Tim pelaksana, petani mitra, dan mahasiswa terlibat dalam diskusi yang menarik. Dalam diskusi juga dibahas potensi untuk mengolah produk cabe merah menjadi produk yang bisa memopunyai daya simpan lebih lama terutama disaat harga cabe anjlok.

\section{Pelatihan Pembuatan Cabe Kering dan Cabe Bubuk}

Pelatihan pembuatan cabe kering dan bubuk cabe merupakan kegiatan inti untuk menjawab kebutuhan petani dalam teknologi tepat guna yang bisa memperpanjang daya simpan cabe merah segar agar tidak cepat busuk dan mengakibatkan kerugian bagi petani. Dari diskusi saat pelatihan terungkap bahwa ibuk-ibuk petani sudah lama ingin mempelajari teknologi tepat guna pengolahan cabe merah segar menjadi olahan cabe yang bernilai ekonomi dan memiliki daya simpan yang lebih panjang sehingga dapat mengatasi salah permasalahan yang dialami petani yaitu cabe berlimpah di musim panen raya dan mereka kekurangan cabe disaat paceklik dan harga cabe melambung tinggi.

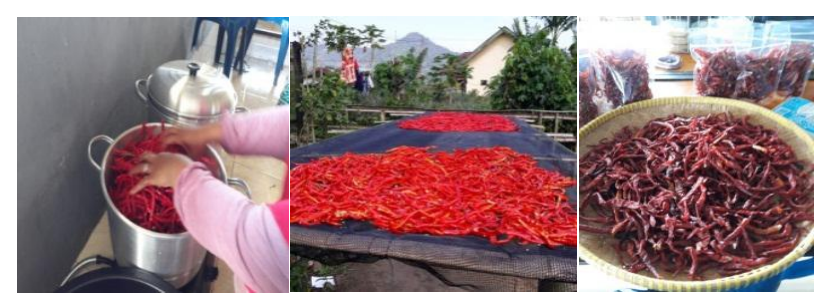

Gambar 4. Pembuatan Cabe Kering

Pembuatan cabe kering diawali dengan pensortiran cabe hasil panen petani, pembuangan tampuk dan selanjutnya dicuci dalam bascom besar. Cabe yang sudah bersih sebagian dibelah dengan pisau stainless untuk kebutuhan cabe kering yang dibelah. Selanjutnya untuk mempertahankan warna merah cabe agar tidak menjadi kecoklatan cabe dikukus (blanching) sekitar 5 menit dalam dandang panas dengan kondisi air mendidih. Selanjutnya cabe dikeringkan dengan menjemur dibawah terik matahari diatas para-para yang sudah disiapkan khusus untuk pencjemuran cabe yang sudah dikukus. Penjemuran dengan panas matahari dilakukan 5 sampai 7 hari tergantung cuaca, dan cabe yang telah kering ditandai dengan kondisi cabe yang sudah mudah patah dengan bobot yang lebih ringan dengan kandungan air 15 sampai dengan $20 \%$. Selanjutnya untuk membuat cabe bubuk dilakukan dengan penggilingan cabe kering dengan mesin penepung yang sudah disiapkan.
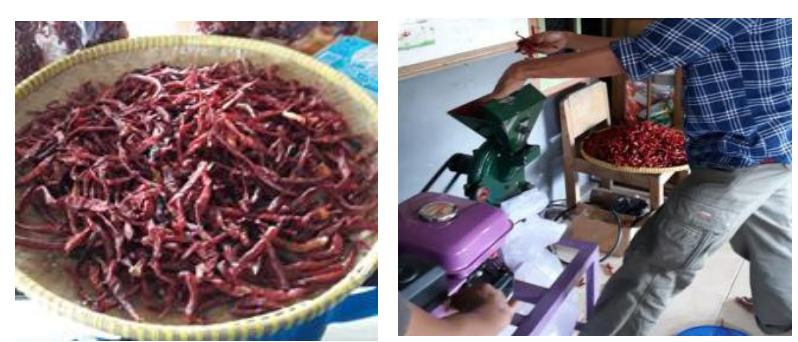

Gambar 5. Penggilingan Cabe Bubuk 


\section{Pelatihan Pembuatan Abon Cabe, Pasta Cabe dan} Aneka Saos Cabe

Selain pengolahan cabe dlam bentuk cabe kering dan bubuk cabe, juga dilakukan pelatihan pengolahan cabe dalam bentuk olahan seperti pasta cabe dan bermacam saos cabe seperti saos cabe murni, saos cabe tomat, saos cabe nanas. Hal ini dimaksudkan untuk menambah wawasan dan keterampilan ibu-ibu wanita tani dalam membuat olahan aneka cabe.
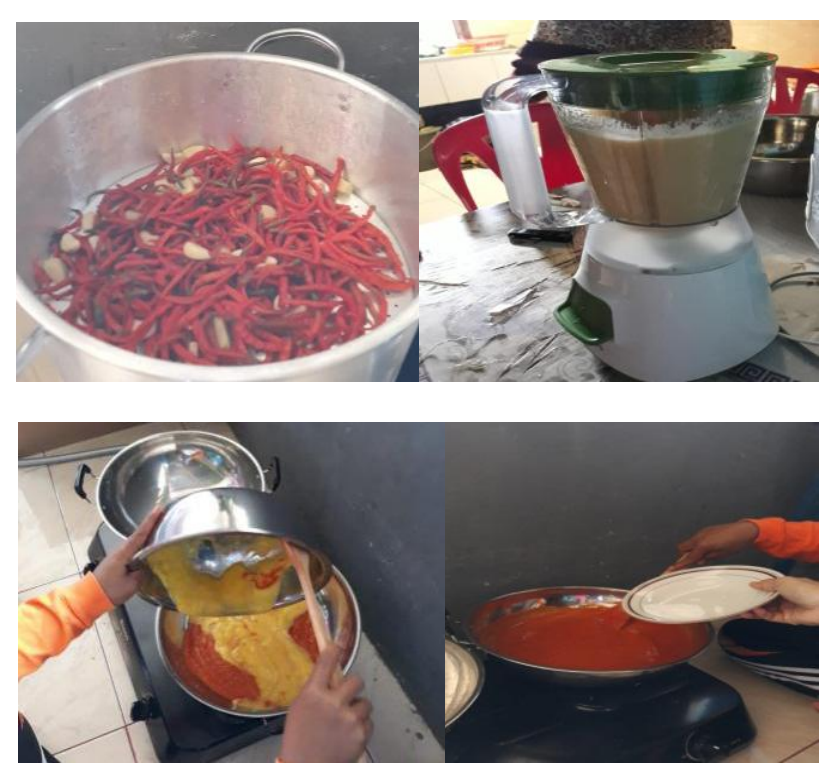

Gambar 6. Pembuatan Berbagai Olahan Cabe

\section{Pendampingan Kelompok Tani Mitra}

Pendampingan dilakukan agar kelompok wanita tani mitra PKM merasa terbimbing dan percaya diri mempraktekkan keterampilan yang sudah mereka dapatkan dalam mengolah cabe merah menjadi aneka produk yang memiliki masa simpan lebih lama serta mempunyai nilai tambah secara ekonomi. Walaupun semua materi kegiatan pelatihan pengolahan cabe merah sudah dilaksanakan, akan tetapi untuk menjamin keberhasilan program maka pendampingan lapangan tetap dilaksanakan sampai akhir bulan November 2018.

\section{ULASAN KARYA}

Dari kegiatan PKM yang telah dilakukan terlihat bahwa ibu-ibu anggota kelompok mitra sangat antusias dalam mengikuti semua tahapan kegiatan program. Dari interaksi tim pelaksana kegiatan dengan anggota kelompok tani mitra juga diketahui bahwa selama ini mereka tidak menguasai sama sekali dan belum pernah mendapatkan pelatihan dalam pengelolaan cabe merah. Kegalauan mereka disaat harga cabe anjlok dan produksi melimpah sudah menemukan solusi melalui teknologi pengolahan cabe merah. Disaat produksi cabenya melimpah, petani sudah bisa mengolahnya menjadi aneka olahan cabe yang memiliki umur simpan yang lebih lama terutama dalam bentuk olahan cabe kering dan bubuk cabe dan bisa dimanfaatkan disaat harga cabe meroket atau terjadi gagal panen.

Melihat nilai ekonomis aneka olahan cabe merah cukup prospektif di pasaran dan Kecamatan Kabawetan juga sebagai salah satu tujuan wisata potensial (kebun teh) maka dimasa yang akan datang aneka olahan cabe merah ini juga bisa dijadikan sebagai salah satu produk yang bisa dijual sebagai oleh-oleh bagi wisatawan yang berkunjung ke Kecamatan Kabawetan.

Dari evaluasi dan diskusi dengan kelompok mitra, juga diketahui bahwa agar produk yang dihasilkan bisa laku dipasaran perlu dilakukan peckaging yang lebih menarik serta promosi produk melalui media sosial.

\section{KESIMPULAN}

PKM yang telah dilaksanakan telah dapat menambah wawasan dan keterampilan tani mitra dalam mengolah cabe merah menjadi aneka olahan cabe yang memiliki masa simpan yang lebih panjang dan nilai ekonomis yang lebih tinggi.

\section{DAMPAK DAN MANFAAT KEGIATAN}

Program Kemitraan Masyarakat (PKM) teknologi pengolahan cabe merah merupakan transfer dan penerapan teknologi tepat guna ke tengah lingkungan masyarakat. Masyarakat petani cabe merah yang sebelumnya tidak memiliki keterampilan sama sekali dalam pengolahan cabe merah saat ini sudah mampu dan mandiri dalam membuat aneka olahan cabe merah. Produk cabe merah yang melimpah di saat panen raya, 
saat ini sudah mulai diolah masyarakat menjadi produk olahan terutama dalam bentuk cabe bubuk yang sangat bermanfaat bagi petani disaat produksi cabe merah anjlok di saat musim penghujan.

\section{DAFTAR PUSTAKA}

[1] Balai Penyuluhan Pertanian, Perikanan dan Kehutanan (BP3K) Kecamatan Kabawetan Kabupaten Kepahiang. Programa Penyuluhan Pertanian Tahun 2016, 2016.

[2] Jumasdan. Studi Pengaruh Penambahan $\mathrm{Gas}^{\mathrm{CO}_{2}}$ Terhadap Umur Simpan Cabe Keriting (Capsicum annum var) Tanpa Bkanching. Program Studi Ilmu Dan Teknologi Pangan. Jurusan Teknologi Pertanian. Fakultas Pertanian Universitas Hasanuddin. Makasar, 2012.

[3] Santoso, M.B. dan Madya, W. Penanganan Pasacapanen Tanaman Hortikultura. Balai Besar Pelatihan Pertanian (BBPP) Binuang Kalimantan Selatan, 2013.

\section{PENGHARGAAN}

Terima kasih banyak kami sampaikan kepada DRPM Kemenristekdikti yang telah mendanai kegiatan pengabdian kepada masyarakat ini melalui Hibah Program Kemitraan Masyarakat (PKM) Tahun Anggaran 2018. 